Open Access

\title{
Assessing healthcare service quality: a comparative study of patient treatment types
}

\author{
DonHee Lee ${ }^{1^{*}}$ (D) and Kai K. Kim²
}

\author{
* Correspondence: dhlee@kmu.ac.kr \\ ${ }^{1}$ College of Business Administration, \\ Keimyung University, 1095 \\ Dalgubeol-daero, Daegu, South \\ Korea \\ Full list of author information is \\ available at the end of the article
}

\begin{abstract}
The purpose of this study is to examine the effects of healthcare service quality (HEALTHQUAL) measurement items. First, the proposed measurement items for HEALTHQUAL were tested using data collected from a hospital in South Korea with more than 500 beds. The data set included 365 patients and 232 public respondents. ANOVA and t-tests were used to perform a comparative analysis of HEALTHQUAL measurement items among three patient treatment groups (inpatients, outpatients, and family members of patients in the emergency room) and between the patient and general public groups. The results indicated significant differences among measurement items of HEALTHQUAL depending on the type of patient treatment, while there were no significant differences among measurement items of HEALTHQUAL between patients and the public.
\end{abstract}

Keywords: Healthcare service quality, HEALTHQUAL measurement items, Type of patient treatment

\section{Background}

Healthcare has recently received much attention as it is the fastest growing service industry around the globe [1-3]. Concerns for healthcare quality and patient safety have increased, especially in the context of cost, malpractice, and healthcare reform [1-9]. Research has shown that both patients and care provider staff prioritize the availability of clinical service options, as well as an environment which is safe and secure, clean, comfortable, quiet and pleasant to practice and receive medical care.

The fundamental value of service in the healthcare industry can be distinguished from other services, thus raising the challenge of assessing comparative service quality of care providers in this complex industry. Myers [10] first introduced the concept of healthcare service quality, which has been measured using several dimensions [e.g., 11-15]. Measurement items of healthcare service quality have evolved and shifted based on research agenda [e.g., 2, 13, 16, 17]. Managing service quality within a hospital requires an efficient approach for gathering feedback on the care provided. Healthcare providers should examine the perceptions of a variety of stakeholders including patients, physicians, nurses, and others to create a more comprehensive view of service quality.

Although previous studies focused on evaluations of healthcare service quality based on various approaches (SERVQUAL, SERVPERF, or mixed models), Lee [3] proposed HEALTHQUAL, a model of healthcare service quality measurement

(c) The Author(s). 2017 Open Access This article is distributed under the terms of the Creative Commons Attribution 4.0 International License (http://creativecommons.org/licenses/by/4.0/), which permits unrestricted use, distribution, and reproduction in any medium provided you give appropriate credit to the original author(s) and the source, provide a link to the Creative Commons license, and indicate if changes were made. 
items by focusing on care processes and results. HEALTHQUAL consists of five components: empathy, tangibles, safety, efficiency, and degree of improvements of care service.

There is a paucity of research that tested mean differences of service quality measurement items among different healthcare user groups (e.g., type of patients, the patient's family members and general public) in a hospital setting. Building on Lee's [3] work, the present study focuses on analysis of mean differences among different healthcare user groups and apply the results to improve care quality specific to different treatment experiences (e.g., inpatient, outpatient and emergency). This study proposes a research model to examine mean differences in healthcare service quality among different healthcare user groups. The rest of this paper is organized as follows: Section 2 presents a review of relevant literature; Section 3 proposes methods; Section 4 provides the result; and Section 5 presents the Discussion and conclusions of the study.

\section{Review of relevant literature}

\section{Healthcare service quality}

Donabedian [11] defined healthcare service quality as "the application of medical science and technology in a manner that maximizes its benefit to health without correspondingly increasing the risk." While this study reflected a definition that emphasizes the evaluation of benefit to risk, Leebov et al. [18] highlighted the assessment of progressive and preventative measures: "doing the right thing and making continuous improvements, obtaining the best possible clinical outcome, satisfying all customers, retaining talented staff and maintain sound financial performance." These definitions emphasize that healthcare service quality is delivered to satisfy customer expectations and patient needs, as well as to improve care by skilled professional providers. However, healthcare service quality is difficult to define and measure depending on the type of treatment, perception of patients, and interactions between patients and providers including characteristics of care service and ethical culture of the hospital.

Myers [10] presented accessibility, effectiveness, improvement of care quality, and continuity as items for healthcare service quality. Donabedian [11] reported items of quality measurements as efficacy, effectiveness, efficiency, legitimacy, optimality, acceptability and equity. While both Myers [10] and Donabedian [11] emphasized efficiency and effectiveness as measurement items, Donabedian [11] also introduced equity and efficacy to the patient care experience as additional items. The above studies seem to emphasize the need for patient-oriented medical services rather than the healthcare center-oriented approach. This trend represents the transition of healthcare service from the 1980s concept, which emphasized efficiency, effectiveness, and equitable treatment of patients. This shift in focus in healthcare service evaluation from the doctor to the patient prompted healthcare providers to be responsible for educating patients versus dictating to patients, thus expanding the definition of the quality care experience/service. Vuori [12] reinforced Myers [10] and Donabedian's [11] studies by presenting effectiveness, efficiency, and adequacy as analysis items, and contributed to the list by evaluating quality improvements of scientific-technical competence as properties of quality measurements. 
Parasuraman et al. [19] suggested five dimensions: tangibles, the external factors such as physical facility, equipment, and employees' appearance; reliability, the fulfillment factor of promise to the patient; responsiveness, the attitude of medical workers who nurse, care, and provide immediate service to the patient; assurance, the trust and faith to the patient concerning ability, qualification, and attitude of employees; and lastly, empathy, the attentions and considerations for each patient. This study is well known as the SERVQUAL (service quality) model and is one of the widely used models to measure quality in service areas because of its comprehensiveness and practical applicability.

Cronin and Taylor [20] proposed the weighed SERVPERF (service performance) model, which integrates SERVPERF and SERVPERF with importance. SERVPERF, based on five dimensions and 22 items of SERVQUAL, emphasizes appropriateness to measure the quality of service by including the perception of quality performance. While SERVQUAL measures the difference between the perception of consumers about the performance of a service provider and expectations of consumers, SERVPERF is different from SERVQUAL in that it uses quality items to measure service quality.

Carmen [21] reported six quality items: tangibles, reliability, safety, empathy (similar to Parasuraman et al. [19]), convenience, and cost. Bowers et al. [13] proposed reliability, responsiveness, communication, accessibility, and understanding and consideration of the patient as healthcare service quality items. Jun et al. [14] suggested that healthcare service quality should be measured based on the patient's perceptions, and presented 11 dimensions: tangibles, reliability, responsiveness, technology, competence, courtesy, communication, collaboration, caring, accessibility, customer understanding, and patient outcomes. Mostafa [22] and Yesilada and Direktor [23] recommended measuring healthcare service quality through empathy, reliability, and tangibles, based on the SERVQUAL model. Ranjbar et al. [24] and Kalepu [25] also studied healthcare quality using the SERVQUAL model.

Donaldson [26] argued that quality measurement of healthcare service should include the various quality concepts of healthcare service defined by IOM [27]. For example, quality measurements may include: the documented data for quality improvement efforts; the inspection of facilities and individuals against standards; the provisions of right-to-know with regard to the patient's or family members' decision-making for treatments; the controls and reports about healthcare service based on times; and the provided healthcare information to the community.

Shelton [15] presented four categories: accessibility, communication, efficiency, and perceived quality, care, and medical facility and devices. Doran and Smith [28] categorized measurement items of healthcare service quality as empathy, responsiveness, reliability assurance and improvement of care services. Choi et al. [29] mentioned convenience of the care process that may be related to administration, such as waiting time for medical examinations, quick and simple payment procedure, efficiency; tangible as equipment; and staff and physician concerns including service quality aspects related to physicians' and nurses' abilities to explain the medical treatment process to the patient, friendliness and helpfulness. While studies of Shelton [15] and Doran and Smith [28] did not significantly depart from SERVQUA, Choi et al.'s study [29] added external care activities such as waiting time and billing procedures to the list. 
Scobie et al. [16] reported the following measurement items of healthcare service quality: accessibility, tangibles, efficient costs, values, timeliness, policy and implementation to improve quality, understanding the expected value of customers, and capabilities of the hospital. Evans and Lindsay [17] introduced the following six dimensions of healthcare service quality: the disease-centered aspect; the patient-centered; treatment types-centered; functioncentered; the center of the comprehensive aspect; and the expert-centered. Scobie et al.'s [16] study added the capacity or capability of a healthcare institution. Lee [3] proposed HEALTHQUAL, a set of measurement items for healthcare service quality, based on the type of care service (provider aspect) and patient. She also proposed the five most important criteria for evaluating healthcare providers. Then, HEALTHQUAL has five dimensions: the degree of improvements of care services, tangible quality aspects, efficiency quality aspects, safety quality aspects, and empathy quality aspects.

As reviewed above, various measurement items for healthcare service quality have been proposed and modified based on the researcher's viewpoints. Thus, healthcare service quality can be measured according to the researcher's viewpoints on patients and providers, the type of medical treatment, and medical equipment and systems used. HEALTHQUAL by Lee [3] is an integrated model to measure healthcare service quality based on the patient's view, the hospital view, and the perspective of accreditation institutions.

Healthcare service decisions are driven by inputs such as needed resources, including medical staff, equipment and systems, patients, and/or medicine. Analysis of how these resources are used to treat the patient (wellness/illness) and also to address the patient experience, including requests for empathetic staff, comfortable and safe structures, and advanced equipment and systems, is important. Thus, healthcare organizations make inventory and allocation decisions based on the measurement of these resources. Also, as efficiency is positively and strongly correlated to the utilization of resources, it may impact the improvement of care service-as the most valuable item for the patient.

Considering Lee's [3] study, this study adopted the following measurement items of healthcare service quality: empathy, tangibles, safety, efficiency, and improvement of care services. For this study, empathy refers to an attitude of the provider to better serve patients by actively listening and reflecting patients' emotions while providing care services. Tangibles refer to the use of advanced medical equipment and the physical environment to provide proper care services emphasizing the value of place. Safety refers to the provider's capacity to maintain a comfortable and safe environment for patients, potential consumers, and employees in the hospital. The quality aspect of efficiency refers to how efficiently the provider makes efforts to utilize medical resources when delivering patient care services for the medical costs associated. Improvements of care services, in the context of quality, refers to the best efforts of staff on care service processes, communications, and interactions with patients, and the result of patients' effort to improve their own disease.

\section{Methods}

\section{Research model and methods}

Considering Lee's [3] work, Fig. 1 presents the research model to examine HEALTHQUAL through two groups. Measurement items reflect the notion that when patients and 


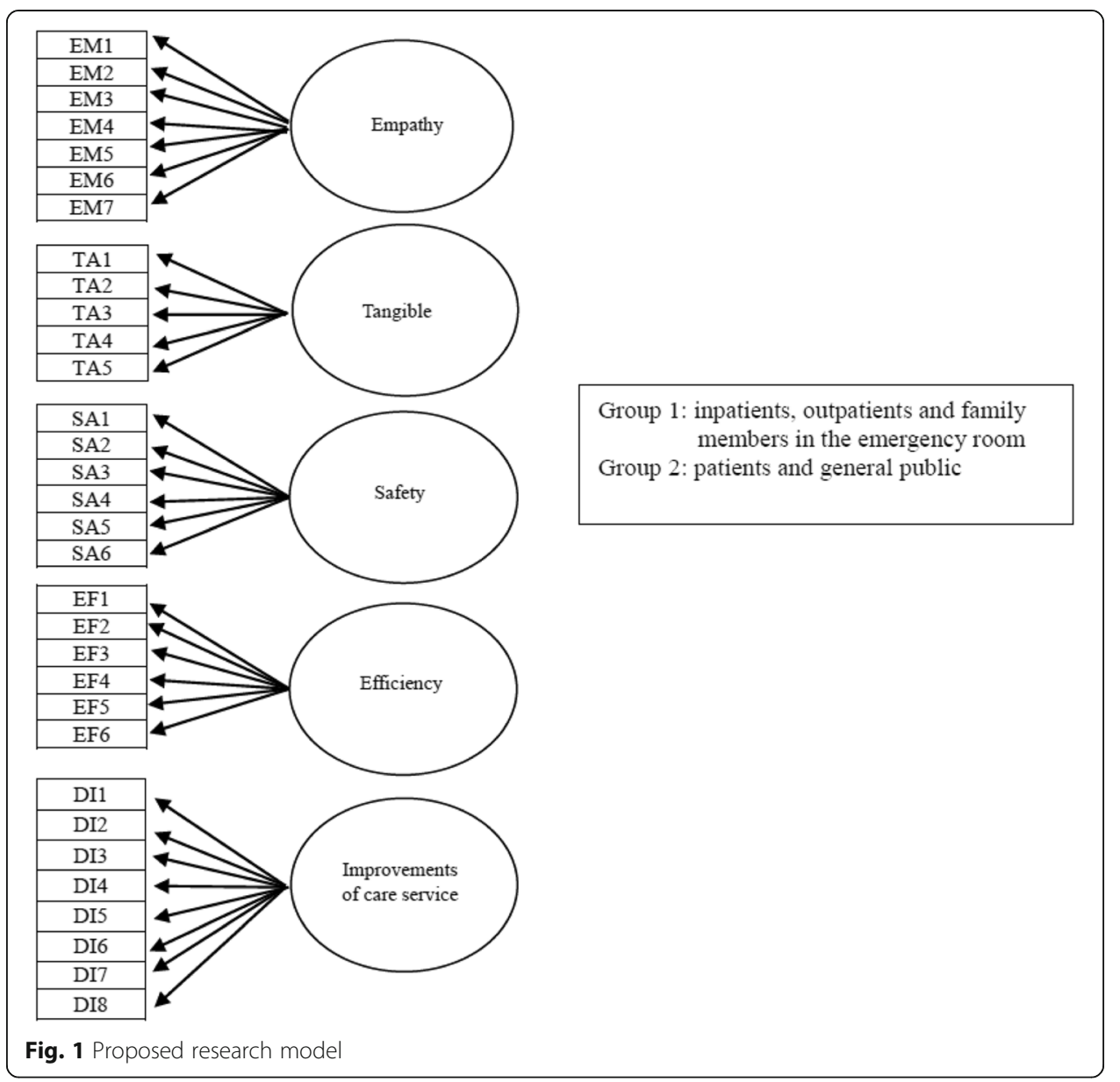

their family members choose a hospital, they usually have certain expectations or perceptions about the quality of care and services offered by the hospital as patients directly or indirectly obtain prior knowledge about the provider. Also, the results of care treatments can either improve or worsen the patient's condition through the efforts of medical staff and the willingness of the patient.

As shown in Fig. 1, two group were formed for analysis. Group 1 included inpatients (IN), outpatients (OUT), and family members of patients in the emergency room (EM) for the analysis of quality measurement items based on the treatment type. Group 2 included patients (only IN and OUT, excluding EM) and general public to ascertain their differences in quality measurement items.

\section{Data collection}

To test the proposed measurement items of HEALTHQUAL, we collaborated with director of quality improvement at a hospital in Seoul, south Korea. We shall call this hospital "K-hospital", which is a tertiary hospital with more than 500 beds. We developed a survey questionnaire and it was tested with patients and/or patients' family members in a pilot survey involving 30 patients in a hospital in K-hospital. The pilot test was undertaken to assure the participants clearly understood the questionnaire items. After the pilot test, some items were modified to improve clarity and understanding. Participation in this survey was voluntary. 
To collect data, first, inpatients, outpatients, and family members of the patients in the emergency room were selected. Five hundred questionnaires were distributed to the patients in K-hospital. The process for data collection included visiting with inpatients, outpatients, and the family members of the patients in the emergency room who had contact with a doctor, nurse, or technician. Then, we requested their cooperation in responding to our survey questionnaire. If they agreed to participate, they would fill out the questionnaire in about 15-20 min. If participants requested the researcher to read the questionnaire, we read the items and marked their answers.

For inpatients or their family members, we used the following criteria: 1) their hospital stay lasted longer than 7 days but less than 13 days, based on the average length of stay (the OECD average was 8.5 days in 2012, while the Korean average was 16.1 days in 2012, and the OECD average was 4.8 , while the Korean average was 10.3 beds per 1,000 people in 2012); 2) they used a multi-patient room (2 or more beds in one room); 3 ) they were to be discharged the next day from the hospital; and 4) terminally or critically ill patients were excluded from the study. For outpatients or their family members, we randomly distributed the questionnaires. Considering the emergency room patients are usually terminally or critically ill, we contacted family members who were waiting in the emergency room. If they agreed to participate, the questionnaire was distributed. However, if the emergency situation prevented the participant from filling out the questionnaire, then we discarded incomplete questionnaires. We also distributed the questionnaires to the public, defined as those who were just visiting their family members or friends at the hospital and did not received medical treatment within the last 3 months.

Out of 500 questionnaires distributed to patients or family members, we received 405 (81.0\%) responses. Additionally, we received 267 (53.4\%) of public responses. Questionnaires with incomplete or missing items were discarded, so we used $365(73.0 \%)$ of the patient group and $232(46.4 \%)$ of the public group.

As shown in Table 1, the majority of patient respondents had the experience of receiving medical treatment and/or diagnosis within the past 3 months in a hospital $(65.2 \%)$, while only $34.8 \%$ of patient respondents did not have previous care experiences. Patient respondents experienced the following care service areas: outpatient (37.8\%), inpatient (34.2\%), and ER (emergency room, 27.9\%).

\section{Variables}

The questionnaire measured the constructs using a 5-point Likert scale. Scales to measure each of the constructs were developed primarily based on prior studies. The study employed SPSS 17.0 and AMOS 17.0 programs. Table 2 showed the mean for each variable ranging from 3.02 (DI1) to 3.98 (SA2) and the standard deviation ranged from .74 (TA2) to 1.51 (SA2).

Reliability was tested based on Cronbach's alpha value (Table 3). All of the coefficients of reliability for the constructs exceeded the threshold value of .70 for exploratory constructs in basic research [30]. In the reliability test, the Cronbach's alpha value for empathy was the highest with .932 and tangible was the lowest, .807. All of the Cronbach's alpha values for the five latent variables were significant at $p<.05$.

For the validity test, principal component analysis (PCA) and confirmatory factor analysis (CFA) were performed to identify the most meaningful basis and to identify similarities and differences in the data. Among the measurement items, 32 variables 
Table 1 Characteristics of respondents at K-hospital

\begin{tabular}{|c|c|c|c|c|c|c|}
\hline \multirow{2}{*}{\multicolumn{2}{|c|}{ Items }} & \multicolumn{3}{|c|}{ Frequency (\%) } & \multirow{2}{*}{\multicolumn{2}{|c|}{$\frac{\text { Frequency (\%) }}{\text { General Public }}$}} \\
\hline & & \multicolumn{3}{|l|}{ Patients } & & \\
\hline \multirow[t]{4}{*}{ Gender } & Male & $156(42.7 \%)$ & Outpatient & $138(37.8 \%)$ & Male & $\begin{array}{l}78 \\
(33.6 \%)\end{array}$ \\
\hline & Female & 209 (57.3\%) & Inpatient & $125(34.2 \%)$ & Female & $\begin{array}{l}154 \\
(66.4 \%)\end{array}$ \\
\hline & & & ER & 102 (27.9\%) & & \\
\hline & Total & 365 (100.0\%) & & & $232(10$ & \\
\hline \multirow{2}{*}{\multicolumn{2}{|c|}{$\begin{array}{l}\text { Medical experiences } \\
\text { within } 3 \text { months } \\
\text { at this hospital }\end{array}$}} & Yes & $238(65.2 \%)$ & & Yes & $0.0 \%$ \\
\hline & & No & $127(34.8 \%)$ & & No & $\begin{array}{l}232 \\
(100.0 \%)\end{array}$ \\
\hline \multirow[t]{11}{*}{ Occupation } & Homemaker & 61 & 16.7 & & 53 & 22.8 \\
\hline & Student & 41 & 11.2 & & 31 & 13.4 \\
\hline & $\begin{array}{l}\text { Office } \\
\text { worker }\end{array}$ & 38 & 10.4 & & 29 & 12.5 \\
\hline & Professional & 32 & 8.8 & & 22 & 9.5 \\
\hline & $\begin{array}{l}\text { Owner- } \\
\text { operator }\end{array}$ & 16 & 4.4 & & 11 & 4.7 \\
\hline & $\begin{array}{l}\text { Public } \\
\text { official }\end{array}$ & 37 & 10.1 & & 23 & 9.9 \\
\hline & $\begin{array}{l}\text { Business } \\
\text { person }\end{array}$ & 39 & 10.7 & & 7 & 3.0 \\
\hline & Military & 3 & 0.8 & & 0 & 0.0 \\
\hline & Unemployed & 79 & 21.6 & & 27 & 11.6 \\
\hline & Other & 19 & 5.2 & & 29 & 12.5 \\
\hline & Total & 365 & $100.0 \%$ & & 232 & $100.0 \%$ \\
\hline
\end{tabular}

were identified in the five components. These variables with less than .5 loading values were removed from the study: two variables in safety (SA5 and SA6), efficiency (EF5 and EF6), and improvements of care services (DI7 and DI8). Thus, these 6 variables were removed from the study.

In the PCA with Varimax rotation, the loadings of the items for the five components provided support for the constructs formulated. The loading values of each factor ranged from .724 to .925. All measurement instruments met the threshold value. Eigen values for empathy, tangibles, safety, efficiency, and degree of improvements of care service were $11.754,1.374,1.124,1.041$ and 2.805 , respectively. The total percentage of variance explained was 69.89, demonstrated by the constructs in Table 3: empathy (49.103), tangible (4.801), safety (4.514), efficiency (4.051), and improvements of care services (7.417).

The results of CFA can provide evidence of the convergent and discriminant validity of theoretical constructs [31]. This model consisted of five components: empathy, tangibles, safety, efficiency, and improvements of care services. Statistics of CFAs are shown in Tables 3 and 4. The results of the goodness of fit test for the measurement model are summarized in Table 4, which showed the values of chi-square ( $\left.\mathrm{x}^{2}\right)$, degrees of freedom, GFI, CFI, TLI, RMSEA, RMR, and $p$-value of the model. Compared to the recommended values for the goodness of fit tests, the values of GFI, AGFI, CFI, TLI, RMR, RMSEA, $\chi^{2}$, and the p-value were satisfactory, whereas the value of GFI (.897) was not. 
Table 2 Measurement items of HEALTHQUAL

\begin{tabular}{|c|c|c|c|}
\hline Dimensions & $\begin{array}{l}\text { Measurement variables } \\
\text { (Likert type 5-point Scale, } 1=\text { Worst; } 5=\text { Outstanding) }\end{array}$ & M & SD \\
\hline \multirow[t]{7}{*}{ Empathy (EM) } & - Polite attitudes of employees (EM1) & 3.32 & .96 \\
\hline & - Explaining the details (EM2) & 3.29 & .98 \\
\hline & - Listen to the patient (EM3) & 3.46 & .8 \\
\hline & - Understand and consider the patient's situation (EM4) & 3.43 & 1.08 \\
\hline & - A sense of closeness and friendliness (EM5) & 3.28 & 1.01 \\
\hline & - Hospital knows what the patient wants (EM6) & 3.59 & .91 \\
\hline & - Hospital understands the patient's problems as empathy (EM7) & 3.17 & .89 \\
\hline \multirow[t]{5}{*}{ Tangible (TA) } & - Degree of securing advanced medical equipment (TA1) & 3.84 & .81 \\
\hline & $\begin{array}{l}\text { - Degree of securing medical staff with advanced skills and } \\
\text { knowledge (TA2) }\end{array}$ & 3.82 & 1.21 \\
\hline & - Degree of convenient facilities (TA3) & 3.43 & .98 \\
\hline & - Degree of cleanliness of employee uniforms (TA4) & 3.61 & .78 \\
\hline & - Overall cleanliness of the hospital (TA5) & 3.53 & .74 \\
\hline \multirow[t]{6}{*}{ Safety (SA) } & $\begin{array}{l}\text { - Degree of a comfortable and safe environment for receiving } \\
\text { treatment (SA1) }\end{array}$ & 3.78 & .96 \\
\hline & $\begin{array}{l}\text { - Degree of the feeling that doctors would not make } \\
\text { misdiagnoses (SA2) }\end{array}$ & 3.93 & 1.51 \\
\hline & - Degree of the feeling that nurses would not make mistakes (SA3) & 3.21 & .83 \\
\hline & - Degree of confidence about the medical proficiency of this hospital (SA4) & 3.38 & .94 \\
\hline & - Degree of a hospital environment that is safe from infection (SA5) & 3.45 & .92 \\
\hline & - Degree of a comfortable and safe environment for patients (SA6) & 3.58 & 1.05 \\
\hline \multirow[t]{6}{*}{ Efficiency (EF) } & - Attitudes about not using unnecessary medication(EF1) & 3.25 & .78 \\
\hline & - Degree of efforts for proving appropriate treatment methods (EF2) & 3.37 & 1.05 \\
\hline & - Reasonable medical expenses(EF3) & 3.05 & .84 \\
\hline & - Appropriateness of cost for medical services provided (EF4) & 3.37 & .79 \\
\hline & - Degree of convenience for treatment procedures (EF5) & 3.45 & 1.01 \\
\hline & - Degree of efforts for reducing unnecessary procedures (EF6) & 3.71 & 1.24 \\
\hline \multirow{8}{*}{$\begin{array}{l}\text { Improvements of } \\
\text { care service (DI) }\end{array}$} & - Appropriateness of care service provided (DI1) & 3.02 & .87 \\
\hline & $\begin{array}{l}\text { - Recognition and efforts for the best treatment by the } \\
\text { medical staff (DI2) }\end{array}$ & 3.85 & .92 \\
\hline & $\begin{array}{l}\text { - Improvement in medical condition as a result of efforts } \\
\text { and treatment (DI3) }\end{array}$ & 3.07 & 1.05 \\
\hline & $\begin{array}{l}\text { - Degree of improved patient condition after using this } \\
\text { hospital care(D/4) }\end{array}$ & 3.54 & 1.21 \\
\hline & $\begin{array}{l}\text { - Degree of explanations to the patient to prevent } \\
\text { related diseases (DI5) }\end{array}$ & 3.24 & .88 \\
\hline & - Degree of efforts and willingness to prevent disease (DI6) & 3.18 & .94 \\
\hline & - Improvement of disease through this hospital's treatment (DI7) & 3.47 & 1.01 \\
\hline & - Degrees of disease prevention to communities (DI8) & 3.81 & 1.42 \\
\hline
\end{tabular}

All the variables proposed in the study were statistically significant at the .05 level, with the range of standardized factor loadings from .675 to .889. Consequently, fit statistics related with this model confirmed the proposed structure of quality measurements of healthcare service. Therefore, HEALTHQUAL can be measured using the five components of empathy, tangibles, safety, efficiency, and improvement of care services. 
Table 3 Results of reliability and fit indices for PCA and CFA

\begin{tabular}{|c|c|c|c|c|c|c|c|}
\hline \multirow{3}{*}{$\begin{array}{l}\text { Independent } \\
\text { Variables }\end{array}$} & \multicolumn{3}{|l|}{ PCA } & \multicolumn{3}{|l|}{ CFA } & \multirow[t]{3}{*}{ Cronbach's a } \\
\hline & \multirow[t]{2}{*}{ Factor loadings } & \multicolumn{2}{|c|}{ Eigen values } & \multirow[b]{2}{*}{ Standardized loading } & \multirow[b]{2}{*}{ t-value } & \multirow[b]{2}{*}{$p$-value } & \\
\hline & & $\overline{T o t a l}$ & $\overline{\% \text { of variance }}$ & & & & \\
\hline EM1 & .825 & 11.754 & 49.103 & .787 & 17.320 & .000 & .932 \\
\hline EM2 & .845 & & & .765 & 17.149 & .000 & \\
\hline EM3 & .884 & & & .814 & 18.015 & .000 & \\
\hline EM4 & .873 & & & .854 & 20.709 & .000 & \\
\hline EM5 & .923 & & & .823 & 18.238 & .000 & \\
\hline EM6 & .873 & & & .821 & 18.172 & .000 & \\
\hline EM7 & .795 & & & .719 & - & - & \\
\hline TA1 & .742 & & & .701 & 10.015 & .000 & \\
\hline TA2 & .769 & & & .684 & 9.582 & .000 & \\
\hline TA3 & .784 & 1.374 & 4.801 & .721 & 10.206 & .000 & .807 \\
\hline TA4 & .783 & & & .718 & 10.145 & .000 & \\
\hline TA5 & .725 & & & .675 & - & - & \\
\hline SA1 & .802 & & & .784 & 16.145 & .000 & \\
\hline SA2 & .925 & 1.124 & 4.514 & .889 & 21.524 & .000 & .872 \\
\hline SA3 & .854 & & & .827 & 19.450 & .000 & \\
\hline SA4 & .884 & & & .855 & - & - & \\
\hline EF1 & .821 & & & .784 & 14.435 & .000 & \\
\hline EF2 & .841 & 1.041 & 4.051 & .798 & 15.045 & .000 & .823 \\
\hline EF3 & .834 & & & .774 & 13.819 & .000 & \\
\hline EF4 & .863 & & & .801 & - & - & \\
\hline DI1 & .854 & 2.805 & 7.417 & .802 & 11.745 & .000 & .842 \\
\hline DI2 & .824 & & & .785 & 11.402 & .000 & \\
\hline DI3 & .809 & & & .794 & 11.514 & .000 & \\
\hline DI4 & .801 & & & .774 & 11.313 & .000 & \\
\hline Dl5 & .778 & & & .701 & 10.962 & .000 & \\
\hline DI6 & .724 & & & .678 & - & - & \\
\hline
\end{tabular}

Table 5 presents the construct reliability (CR) and average variance extracted (AVE) from latent variables, while the off-diagonal elements are the correlation between latent variables. For adequate discriminant validity, the square root of the AVE of any latent variable should be greater than the correlation between this particular latent variable and other latent variables [32]. Given that $C R \geq 0.7$ and AVE $\geq 0.5$ are desirable, as all five latent variables showed CR values greater than 0.8 and AVE was greater than 0.5, the convergent validity of these variables was satisfied. Consequently, discriminant validity and convergent validity were supported for the model as shown in Table 5.

Table 4 Results of fit indices for CFA

\begin{tabular}{lllllllll}
\hline & $X^{2}$ & df & P & GFI & CFI & TLI & RMSEA & RMR \\
\hline Measurement model & 542.425 & 253 & .000 & .897 & .916 & .925 & .052 & .038 \\
Recommended value & & & & $>.9$ & $>.9$ & $>.9$ & $<.08$ & $<.08$ \\
\hline
\end{tabular}

Comparative Fit Index(CFI), Goodness of Fit Index(GFI), Turker-Lewis Index(TLI), Root Mean Square Error of Approximation(RMSEA), Root Mean Square Residual(RMR) 
Table 5 Correlation matrix and average variance extracted (AVE)

\begin{tabular}{llllll}
\hline Constructs & Empathy & Tangibles & Safety & Efficiency & Improvement of care services \\
\hline Empathy & 1 & & & & \\
Tangible & $.612^{* * *}$ & 1 & & & \\
Safety & $.733^{* * *}$ & $.593^{* *}$ & 1 & & \\
Efficiency & $.718^{* * *}$ & $.681^{* * *}$ & $.625^{* * *}$ & 1 & \\
Improvements of care services & $.754^{* * *}$ & $.701^{* * *}$ & $.699^{* * *}$ & $.758^{* *}$ & 1 \\
CR & .943 & .859 & .899 & .865 & .912 \\
AVE & .738 & .693 & .704 & .672 & .647 \\
Sqrt. (AVE) & .859 & .832 & .840 & .820 & .804 \\
\hline
\end{tabular}

$\mathrm{CR}$ (construct reliability) $=\Sigma$ (factor loading $\left.{ }^{2}\right) /\left[\Sigma\right.$ (factor loading $\left.{ }^{2}\right)+\sum$ (error): more than .7

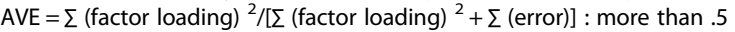

${ }^{* *} p<.01,{ }^{* * *} p<.001$

\section{Results}

\section{Comparative analysis of quality measurement items on treatment type}

Analysis of quality measurement items: inpatients, outpatients, and the emergency room

This study analyzed characteristics of three groups: inpatients (IN), outpatients (OUT), and family members of the patients in the emergency room (EM). To analyze differences and draw multiple comparisons among the three groups, one-way betweengroups analysis of variance (ANOVA) and the Scheffe test were employed. To confirm whether there are significant differences in mean scores on the dependent variable across the three groups, this study developed multiple comparisons using the mean score of measurement items for HEALTHQUAL among the three groups.

In the test of homogeneity of variances, which assesses whether the variance in scores is the same for each of the three groups, the significance values were: empathy $(p=.472)$, tangibles $(p=.324)$, efficiency $(p=.135)$, safety $(p=.359)$, and

Table 6 Results of ANOVA

\begin{tabular}{llrllll}
\hline & & Sum of Squares & DF & Mean Squares & F & p-value \\
\hline Empathy & Between Groups & 13.172 & 2 & 6.586 & 9.450 & $.000^{* * *}$ \\
& Within Groups & 266.225 & 360 & .697 & 9.450 & $.000^{* * *}$ \\
& Total & 279.396 & 362 & & 9.450 & $.000^{* * *}$ \\
Tangibles & Between Groups & 3.812 & 2 & 1.906 & 4.919 & $.008^{* *}$ \\
& Within Groups & 148.006 & 360 & .387 & 4.919 & $.008^{* *}$ \\
& Total & 151.818 & 362 & & 4.919 & $.008^{* *}$ \\
Efficiency & Between Groups & 3.234 & 2 & 1.617 & 3.098 & $.046^{*}$ \\
& Within Groups & 199.386 & 360 & .522 & 3.098 & $.046^{*}$ \\
Safety & 202.619 & 362 & & 3.098 & $.046^{*}$ \\
& Total & 2.665 & 2 & 1.332 & 1.837 & .161 \\
& Between Groups & 277.132 & 360 & .725 & 1.837 & .161 \\
& Within Groups & 279.796 & 362 & & 1.837 & .161 \\
& Total & 4.493 & 2 & 2.246 & 5.949 & $.003^{* *}$ \\
& Between Groups & 144.240 & 360 & .378 & 5.949 & $.003^{* *}$ \\
& Within Groups & 148.732 & 362 & & 5.949 & $.003^{* *}$ \\
\hline
\end{tabular}

${ }^{*} p<.05 * * p<.01 * * * p<.001$ 
improvement of care services $(p=.299)$. As each $\mathrm{p}$-value is greater than .05 , the homogeneity of variances assumption was not violated. As shown in Table 6, there were significant differences among four items, with the exception of the safety item ( $\mathrm{F}=1.837, P=.161)$. The safety item demonstrated no difference based on the type of treatment, indicating that a safe environment is a necessary and expected factor in hospitals.

The Post Hoc test, which measures whether the two groups being compared are significantly different from one another at $p<.05$, was based on the Scheffe test. The results are shown in Table 7 . The analysis showed that the items of efficiency and safety had no statistical difference among patient groups. The EM group showed statistically significant difference from IN and OUT on the items of empathy, tangibles, and

Table 7 Result of multiple comparisons

\begin{tabular}{|c|c|c|c|c|c|c|c|}
\hline \multirow{2}{*}{$\begin{array}{l}\text { Dependent } \\
\text { Variable }\end{array}$} & \multirow[t]{2}{*}{ (I) where } & \multirow[t]{2}{*}{ (J) where } & \multirow{2}{*}{$\begin{array}{l}\text { Mean } \\
\text { Difference } \\
(I-J)\end{array}$} & \multirow[t]{2}{*}{ Std. Error } & \multirow[t]{2}{*}{ Sig. } & \multicolumn{2}{|c|}{ 95\% Confidence Interval } \\
\hline & & & & & & Lower Bound & Upper Bound \\
\hline \multirow[t]{8}{*}{ Empathy } & \multirow[t]{2}{*}{ EM } & OUT & $-.39753^{*}$ & .10700 & .001 & -.6605 & -.1346 \\
\hline & & IN & $-.42925^{*}$ & .10816 & .000 & -.6950 & -.1634 \\
\hline & \multirow[t]{2}{*}{ OUT } & EM & $.39753^{*}$ & .10700 & .001 & .1346 & .6605 \\
\hline & & IN & -.03172 & .09999 & .951 & -.2774 & .2140 \\
\hline & \multirow[t]{2}{*}{ IN } & EM & $.42925^{*}$ & .10816 & .000 & .1634 & .6950 \\
\hline & & OUT & .03172 & .09999 & .951 & -.2140 & .2774 \\
\hline & \multirow[t]{2}{*}{ EM } & OUT & $-.23242^{*}$ & .07978 & .015 & -.4285 & -.0364 \\
\hline & & IN & $-.21063^{*}$ & .08065 & .034 & -.4088 & -.0124 \\
\hline \multirow[t]{6}{*}{ Tangibles } & \multirow[t]{2}{*}{ OUT } & EM & $.23242^{*}$ & .07978 & .015 & .0364 & .4285 \\
\hline & & IN & .02179 & .07455 & .958 & -.1614 & .2050 \\
\hline & \multirow[t]{2}{*}{ IN } & EM & $.21063^{*}$ & .08065 & .034 & .0124 & .4088 \\
\hline & & OUT & -.02179 & .07455 & .958 & -.2050 & .1614 \\
\hline & \multirow[t]{2}{*}{ EM } & OUT & -.21555 & .09260 & .068 & -.4431 & .0120 \\
\hline & & IN & -.19166 & .09361 & .124 & -.4217 & .0384 \\
\hline \multirow[t]{6}{*}{ Efficiency } & \multirow[t]{2}{*}{ OUT } & EM & .21555 & .09260 & .068 & -.0120 & .4431 \\
\hline & & IN & .02388 & .08653 & .963 & -.1888 & .2365 \\
\hline & \multirow[t]{2}{*}{ IN } & EM & .19166 & .09361 & .124 & -.0384 & .4217 \\
\hline & & OUT & -.02388 & .08653 & .963 & -.2365 & .1888 \\
\hline & \multirow[t]{2}{*}{ EM } & OUT & -.20217 & .10917 & .181 & -.4704 & .0661 \\
\hline & & IN & -.16093 & .11036 & .346 & -.4321 & .1103 \\
\hline \multirow[t]{6}{*}{ Safety } & \multirow[t]{2}{*}{ OUT } & EM & .20217 & .10917 & .181 & -.0661 & .4704 \\
\hline & & IN & .04124 & .10202 & .922 & -.2095 & .2919 \\
\hline & \multirow[t]{2}{*}{ IN } & EM & .16093 & .11036 & .346 & -.1103 & .4321 \\
\hline & & OUT & -.04124 & .10202 & .922 & -.2919 & .2095 \\
\hline & \multirow[t]{2}{*}{ EM } & OUT & $-.25906^{*}$ & .07876 & .005 & -.4526 & -.0655 \\
\hline & & IN & $-.21682^{*}$ & .07962 & .025 & -.4125 & -.0212 \\
\hline \multirow{4}{*}{$\begin{array}{l}\text { Improvement } \\
\text { of care Services }\end{array}$} & \multirow[t]{2}{*}{ OUT } & EM & $.25906^{*}$ & .07876 & .005 & .0655 & .4526 \\
\hline & & IN & .04224 & .07360 & .848 & -.1386 & .2231 \\
\hline & \multirow[t]{2}{*}{ IN } & EM & $.21682^{*}$ & .07962 & .025 & .0212 & .4125 \\
\hline & & OUT & -.04224 & .07360 & .848 & -.2231 & .1386 \\
\hline
\end{tabular}

*. $p<.05$ 
Table 8 Group statistics

\begin{tabular}{llllcc}
\hline Groups & & $\mathrm{N}$ & Mean & Std. Deviation & Std. Error Mean \\
\hline Empathy & Patients & 263 & 3.5776 & .81686 & .04890 \\
& Publics & 232 & 3.5441 & .86089 & .05434 \\
Tangibles & Patients & 263 & 3.8416 & .62004 & .03712 \\
& publics & 232 & 3.8255 & .71037 & .04484 \\
Safety & Patients & 263 & 3.5484 & .80627 & .04827 \\
& Publics & 232 & 3.5837 & .80186 & .05061 \\
Efficiency & Patients & 263 & 3.5251 & .72270 & .04327 \\
& Publics & 232 & 3.5169 & .72004 & .04545 \\
Improvement of care services & Patients & 263 & 3.7611 & .59980 & .03591 \\
& Publics & 232 & 3.7317 & .63454 & .04005 \\
\hline
\end{tabular}

improvement of care services. There was no significant difference between IN and OUT on HEALTHQUAL in the study.

Significant differences were found between the EM group and IN $(p=.000)$; EM and OUT ( $p=.001)$ in the measurement of the empathy item. The EM group showed a statistically significant relationship with IN (3.575) and OUT (3.607) in the homogenous subset test. The empathy item indicated that hospitals should nurture a good relationship with patients, including internal customers. In one homogenous subset test for tangibles, the EM group revealed a statistically significant association with the IN (.869) and OUT (.891) groups. The results imply that medical equipment and facilities at this hospital were placed conveniently and effectively at care places for the patients. For the improvement of care services, the EM group showed a statistically significant relationship with the IN (3.756) and OUT (3.799) groups in the homogenous subset test. The patient family respondents who visited the emergency room reported that the items of recovery conditions, whether or not the patients felt worse off, and how they were admitted into the hospital or transferred to another specialty hospital influenced their perception, expectations, and experience of care. This study affirms that the care treatment in the emergency room should be with speed and accuracy.

\section{Difference analysis of quality measurement items: patients and public}

This study analyzed characteristics of two sample groups, patients and the public. To analyze differences between the two groups, an independent sample $t$-test was employed to test for statistically significant difference in the mean scores of the two groups. The results are shown in Table 8 . The effect size provides the magnitude of differences between the two groups, thus, we used Cohen's eta squared, which has a value from 0 to 1 and represents the proportion of variance in the dependent variable which is explained by an independent variable.

In this study, we used data collected from inpatients (125) and outpatients (138) to represent the patient group and excluded the emergency room group because the respondents were caretakers rather than care receivers. We compared differences in the empathy, tangibles, safety, efficiency, and degree of improvement of care services score between the patient and public groups. For empathy, there was no significant difference in scores for patients $(\mathrm{M}=3.578, \mathrm{SD}=.817)$ and the public $(\mathrm{M}=3.544$, 
$\mathrm{SD}=.861$ ). The magnitude of differences in the means (mean difference $=.033,95 \%$ CI: -.120 to .177 ) was very small (effect size $=.0003$ ) [33].

As shown in Table 9, there were no significant differences in care quality item scores for the patient and public groups.

\section{Discussion and conclusions}

Today, one of the most frequently discussed aspects of healthcare service quality is the information generated about and from patients, thus, a patient-centered approach should determine improvements and decisions be made during care treatments [3, 11]. Also, organizations need to provide a safe and pleasant treatment environment for not only patients and employees, but also to other general customers of the hospital. The care environment should make patients to feel comfortable and safe when receiving needed services for disease treatments, diagnosis, and prevention during the hospital stay.

Table 9 Independent samples test

\begin{tabular}{|c|c|c|c|c|c|c|c|c|c|c|}
\hline & & \multicolumn{2}{|c|}{$\begin{array}{l}\text { Levene's } \\
\text { Test for } \\
\text { Equality of } \\
\text { Variances }\end{array}$} & \multicolumn{7}{|c|}{$t$-test for Equality of Means } \\
\hline & & \multirow[t]{2}{*}{$\mathrm{F}$} & \multirow[t]{2}{*}{ Sig. } & \multirow[t]{2}{*}{$\mathrm{t}$} & \multirow[t]{2}{*}{$d f$} & \multirow[t]{2}{*}{$\begin{array}{l}\text { Sig. } \\
\text { (2-tailed) }\end{array}$} & \multirow[t]{2}{*}{$\begin{array}{l}\text { Mean } \\
\text { Difference }\end{array}$} & \multirow[t]{2}{*}{$\begin{array}{l}\text { Std. Error } \\
\text { Difference }\end{array}$} & \multicolumn{2}{|c|}{$\begin{array}{l}\text { 95\% Confidence } \\
\text { Interval of the } \\
\text { Difference }\end{array}$} \\
\hline & & & & & & & & & Lower & Upper \\
\hline \multirow[t]{2}{*}{ Empathy } & $\begin{array}{l}\text { Equal } \\
\text { variances } \\
\text { assumed }\end{array}$ & .964 & .327 & .459 & 493 & .646 & .03346 & .07290 & -.10975 & .17668 \\
\hline & $\begin{array}{l}\text { Equal } \\
\text { variances } \\
\text { not } \\
\text { assumed }\end{array}$ & & & .458 & 489.102 & .647 & .03346 & .07310 & -.11016 & .17708 \\
\hline \multirow[t]{2}{*}{ Tangibles } & $\begin{array}{l}\text { Equal } \\
\text { variances } \\
\text { assumed }\end{array}$ & .196 & .658 & .278 & 493 & .781 & .01608 & .05780 & -.09746 & .12962 \\
\hline & $\begin{array}{l}\text { Equal } \\
\text { variances } \\
\text { not } \\
\text { assumed }\end{array}$ & & & .276 & 487.236 & .782 & .01608 & .05821 & -.09829 & .13045 \\
\hline \multirow[t]{2}{*}{ Safety } & $\begin{array}{l}\text { Equal } \\
\text { variances } \\
\text { assumed }\end{array}$ & .009 & .926 & -.504 & 493 & .614 & -.03528 & .06996 & -.17271 & .10216 \\
\hline & $\begin{array}{l}\text { Equal } \\
\text { variances } \\
\text { not } \\
\text { assumed }\end{array}$ & & & -.504 & 489.718 & .614 & -.03528 & .06994 & -.17268 & .10212 \\
\hline \multirow[t]{2}{*}{ Efficiency } & $\begin{array}{l}\text { Equal } \\
\text { variances } \\
\text { assumed }\end{array}$ & .666 & .415 & .130 & 493 & .897 & .00816 & .06276 & -.11514 & .13145 \\
\hline & $\begin{array}{l}\text { Equal } \\
\text { variances } \\
\text { not assumed }\end{array}$ & & & .130 & 489.529 & .897 & .00816 & .06275 & -.11512 & .13143 \\
\hline \multirow[t]{2}{*}{$\begin{array}{l}\text { Improvements } \\
\text { of care services }\end{array}$} & $\begin{array}{l}\text { Equal } \\
\text { variances } \\
\text { assumed }\end{array}$ & .084 & .772 & .547 & 493 & .585 & .02931 & .05363 & -.07605 & .13467 \\
\hline & $\begin{array}{l}\text { Equal } \\
\text { variances } \\
\text { not assumed }\end{array}$ & & & .545 & 487.498 & .586 & .02931 & .05379 & -.07637 & .13499 \\
\hline
\end{tabular}


It is imperative for healthcare organizations to understand what consumers need or want so they can meet or exceed their care service expectations. Accordingly, healthcare organizations can provide a positive patient experience and satisfaction by doing things right for quality care service and interactions with both patient and staff.

When assessing the differences among the three patient groups (inpatients, outpatients, and patients' family members for the emergency), quality measurement items showed that the patient's or their family member's perceptions differed in the care treatment area. Also, the t-test results of differences between the two groups, patients and the public, showed that there was no significant difference in scores of empathy, tangibles, safety, efficiency, and improvement in care services. Thus, hospitals should explore different approaches to improving customer satisfaction and operational efficiency. Even if the type of disease is the same, the result of treatment could show different effects depending on the various characteristics of the patient, the environment (e.g., age, gender, family medical history, geographic location, ethnicity, etc.), and the methods used for disease treatments. Given these results, improving customer satisfaction through medical treatment presents both a challenge and an opportunity for the hospital. Although difficult at times, if care providers employ the best method for customized care services, then they would be able to elicit customers' positive emotions.

Overall, efficient measurement and improvement of healthcare service quality occur when there is a common understanding about what constitutes quality healthcare service for patients as well as the general public. Thus, defining and evaluating healthcare service quality should be the priority in identifying the most crucial values of a healthcare service process according to the type of treatment and different types of patients and the general public.

Considering the research results presented by previous studies [e.g., 1,11-16], this study contributes to the literature by proposing an approach to examine difference among type of patient treatments (IN, OUT, and ER) and between patient reflections and general public comments. Thus, the results of this study can be applied to healthcare service quality improvement and operational efficiency, both of which can influence patient satisfaction and provider performance. Also, this study contributes to the literature by empirically testing Lee's [3] HEALTHQUAL model to evaluate patient satisfaction and provider performance.

This study has several limitations. First, data was collected from patients and their caretakers (or advocates) in a hospital with more than 500 beds in South Korea. Second, the emergency room patients could not participate in the study for obvious reason and thus questionnaires were filled out by their caretakers, shifting the response from experiential to witnessed.

Future research should consider these limitations. The comparative research on quality measurement items could be extended through cross-cultural study samples, including different size and type of hospitals, and also longitudinal analyses of the data. Also, the future study should develop appropriate operational processes for different types of hospitals as hospital characteristics tend to require different types of patient treatments. 


\section{Authors' contributions}

DonHee Lee and Kai K. Kim contributed to the developing research model, data collection and writing of the manuscript. Both authors read and approved the final manuscript.

\section{Author details}

${ }^{1}$ College of Business Administration, Keimyung University, 1095 Dalgubeol-daero, Daegu, South Korea. ${ }^{2}$ Management Department, Bryant University, 1150 Douglas Pike, Smithfield, RI 02917, USA.

Received: 9 November 2016 Accepted: 29 December 2016

Published online: 25 January 2017

\section{References}

1. Lee S, Lee D, Olson D (2013) Health-care quality management using the MBHCP excellence model. Total Qual Manag Bus Excell 24(1-2):119-137

2. Lee D (2015) The effect of operational innovation and QM practices on organizational performance in the healthcare sector. Int J Qual Innov 1(8):1-14

3. Lee D (2016) HEALTHQUAL: a multi-item scale for assessing healthcare service quality. Serv Bus. DOI 10.1007/ s11628-016-0317-2

4. Delaney J, Huselid M (1996) The impact of human resource management practices on perceptions of organizational performance. Acad Manag J 39(4):949-969

5. Meyer S, Collier D (2001) An empirical test of the causal relationships in the Baldrige health care pilot criteria. J Oper Manag 19(4):403-425

6. Wright P, Gardner T, Moynihan L, Allen M (2005) The relationship between HR practices and firm performance: examining causal order. Pers Psychol 58:409-446

7. DeJong D (2009) Quality improvement using the Baldrige criteria for organizational performance excellence. Am J Health Syst Pharm 66(1):1031-1034

8. Raposo M, Alves H, Duarte P (2009) Dimensions of service quality and satisfaction in healthcare: a patient's satisfaction index. Serv Bus 3(1):85-100

9. Hsieh Y, Huang L, Wang C (2012) A framework for the selection of six sigma projects in services: case studies of banking and health care services in Taiwan. Serv Bus 6(2):243-264

10. Myers B (1969) A guide to medical care administration: concepts and principles. American Public Health Association, Washington, DC

11. Donabedian A (1980) The definition of quality and approaches to its assessment. Health Administration Press, Chicago, IL

12. Vuori H (1982) Quality assurance of health services: concepts and methodology. Regional Office for Europe, World Health Organization, Copenhagen. Denmark

13. Bowers M, Swan J, Koehler W (1994) What attributes determine quality and satisfaction with healthcare delivery? Healthcare Manag Rev 19(4):49-55

14. Jun M, Peterson R, Zsidisin G (1998) The identification and measurement of quality dimensions in healthcare: focus group interview results. Healthcare Manag Rev 23(4):81-96

15. Shelton $P$ (2000) Measuring and improving patient satisfaction. An Aspen publishers, Gaithersburg, M

16. Scobie S, Thomson R, Mcneil J, Phillips P (2006) Measurement of the safety and quality of healthcare. Med J Aust 184(10):S51-S55

17. Evans J, Lindsay W (2009) Managing for quality and performance excellence. South-Western Cengage Learning, Mason, $\mathrm{OH}$, pp 128-133

18. Leebov W, Jean C, Ersoz C (2003) The healthcare manager's guide to continuous quality improvement. iUniverse, Bloomington, IN

19. Parasuraman A, Zeithaml V, Berry L (1988) SERVQUAL: a multiple item scale for measuring consumer perceptions of service quality. J Retail 64(1):12-40

20. Cronin J, Taylor S (1992) Measuring service quality: a reexamination and extension. J Mark 56(3):55-68

21. Carmen J (1990) Consumer perceptions of service quality: an assessment of the SERVALQUAL dimensions. J Retail 66(1):33-55

22. Mostafa M (2005) An empirical study of patients' expectations and satisfactions in Egyptian hospitals. Int J Health Care Qual Assur 18(7):516-532

23. Yesilada F, Direktor E (2010) Health service quality: a comparison of public and private hospitals. Afr J Bus Manag 4(6):962-971

24. Ranjbar E, Zare A, Arab M, Nasiri S, Hataminasab S, Bahrami M (2012) Analysis of SERVQUAL in Shahid Sadoghi hospital, Yazd, Iran. Hormozgan Med J 16(4):333-340

25. Kalepu R (2014) Service quality in healthcare sector: an exploratory study on hospitals. IUP J Mark Manag 13(1):7-28

26. Donaldson M (1999) Measuring the quality of healthcare. The National Academies Press, Washington, DC

27. IOM (Institute of Medicine) (2001) Crossing the quality chasm. National Academy Press, Washington, DC

28. Doran D, Smith P (2004) Measuring service quality provision within an eating disorders context. Int J Health Care Qual Assur 17(7):377-388

29. Choi K, Lee H, Kim C, Lee A (2005) The service quality dimensions and patient satisfaction relationships in South Korea: comparisons across gender, age and types of service. J Serv Mark 19(3):140-150

30. Nunnally J (1978) Psychometric theory, 2nd edn. McGraw Hill, New York

31. Brown T (2006) Confirmatory factor analysis for applied research. The Guilford Press, New York

32. Pavlou P, Fygenson M (2006) Understanding and prediction electronic commerce adoption: an extension of the theory of planned behavior. MIS O 30(1):115-143

33. Cohen J (1998) Statistical power analysis for the behavioral science, 2nd edn. Lawrence Erlbaum Associates, Hillsdale, New Jersey 